\title{
PENCEGAHAN PERUBAHAN WARNA PADA KAYU JAMUJU (Podocarpus imbricatus) DAN KISAMPANG (Evodia aromatica BL.) DENGAN BAHAN DASAR DESINFEKTAN (Prevention of Wood Colour Change on Jamuju (Podocarpus imbricatus) and Kisampang (Evodia aromatica BL.) with Desinfectant Based Reagents)
}

\author{
Agus Ismanto \& Mohamad Iqbal \\ Pusat Penelitian dan Pengembangan Keteknikan Kehutanan dan Pengolahan Hasil Hutan \\ Jl. Gunung Batu No. 5. 16610. Telp./Fax: 8633413, 8633378 \\ Email: barlyrita@gmail.com \\ Diterima 13 Pebruari 2013, disetujui 11 Agustus 2013
}

\begin{abstract}
The aim of this research was to study natural discoloration of jamuju (Podocarpus imbricatus) and kisampang (Evodia aromatica BL.) before and after treatment again of temperature, humidity, and heat. Discoloration prevention conducted chemically by using antiseptic containing benzalkonium klorida (formula C), kresol or asam kresilat (formula D) and metbylene bisthyiocyanate (MBT as comparison) either on log that is planed or unplaned and on sawn timber. The MBT efficacy result on jamuju and kisampang sawn timber, and formula C on kisampang timber show that it can prevent blue stain with four weeks protection period. Measurement result for brightness colour of jamuju timber on the planed is about 35,22 (MBT Under the roof-45,22 (C AC) and 10,62 (C outside)-37,14 (KAC) on the unplaned. Whereas, measurement for brightness colour of kisampang timber on the planed is about 45,04 (C AC)-53,42 (K Outside) and 8,24 (MBT Outside)-46,66 (K AC) from standard value 73,5. Measurement result for total colour variation of $\Delta E^{*}$ kisampang timber on the planed is about 8,80 (K outside)-22,56 (K Under the roof) and 21,57 (D AC)-40,19 (C Outside) on the unplaned. Whereas $\Delta E^{*}$ of jamuju timber on the planed is about 20,49 (MBT Outside)-25,65 (D AC) and 23 (C AC)-41,02 (C Outside) on the unplaned.
\end{abstract}

Keywords: Wood type, brightness, colour

\begin{abstract}
ABSTRAK
Penelitian ini bertujuan untuk mempelajari perubahan warna alami kayu jamuju (Podocarpus imbricatus) dan kisampang (Evodia aromatica BL.) sebelum dan sesudah perlakuan karena pengaruh suhu, kelembaban, dan panas. Pencegahan perubahan warna dilakukan secara kimia dengan menggunakan antiseptik yang mengandung bahan aktif benzalkonium klorida (formula C), kresol atau asam kresilat (formula D) dan metilena bis tiosianat (MBT sebagai pembanding) baik pada dolok yang dikuliti maupun tidak dikuliti serta pada kayu gergajian. Hasil pengujian efikasi MBT pada kayu gergajian jamuju dan kisampang, serta formula $C$ pada kayu kisampang mampu mencegah jamur biru dengan masa proteksi empat minggu. Hasil pengukuran kecerahan warna kayu jamuju pada bagian yang diserut berkisar antara 35,22 (MBT Bawah atap)-45,22 (C AC) dan pada bagian yang tidak diserut berkisar antara 10,62 (C Luar)-37,14 (K AC). Sedangkan pengukuran kecerahan warna pada kayu kisampang yang diserut berkisar antara 45,04 (C AC)-53,42 (K Luar) dan yang tidak diserut berkisar antara 8,24 (MBT Luar)-46,66 (K AC) dari nilai kecerahan standar 73,5. Hasil pengukuran total variasi warna $\Delta \mathrm{E}^{*}$ kayu kisampang pada bagian diserut berkisar antara 8,80 (K Luar)-22,56 (K Bawah atap) dan pada bagian tidak diserut berkisar antara 21,57 (D AC)-40,19 (C Luar). Sementara $\Delta \mathrm{E}^{*}$ pada kayu jamuju pada bagian
\end{abstract}


JURNAL Penelitian Hasil Hutan Vol. 31 No. 3, September 2013: 213-220

diserut antara 20,49 (MBT Luar)-25,65 (D AC) dan pada bagian tidak diserut antara 23 (C AC)-41,02 (C Luar).

Kata kunci: Jenis kayu, kecerahan, warna

\section{PENDAHULUAN}

Kayu memiliki variasi warna alami dan corak yang dekoratif sehingga banyak dimanfaatkan untuk membuat barang yang bernilai seni tinggi. Namun pada pengolahannya warna kayu dapat berubah. Perubahan warna kayu dapat disebabkan oleh faktor biologis, fisis maupun kimia. Perubahan ini dapat terjadi pada kayu dalam keadaan segar, dalam proses pengolahan maupun pada penggunaan kayu dalam produk akhir. Perubahan warna kayu ini tidak disukai oleh konsumen, sehingga apabila terjadi perubahan warna pada kayu atau produk akhirnya maka kayu tersebut akan dianggap cacat dan memiliki nilai yang rendah dibandingkan kayu sejenis yang normal (Balfas, 1998). Hal ini dapat mengakibatkan jatuhnya harga jual kayu di pasaran.

Secara umum perubahan warna kayu ini berarti hilangnya warna kayu atau discoloration dari cerah menjadi suram atau dari warna tua menjadi muda. Faktor biologis yang sering dijumpai dan menyebabkan perubahan warna pada kayu adalah jamur atau bakteri. Adapun serangan akibat jamur yang sering dijumpai yang mengakibatkan berubahnya warna kayu menjadi biru yang lebih dikenal dengan istilah "Blue Stain". Jamur biru (blue stain) mudah tumbuh pada kayu gubal dan semua jenis kayu, tetapi tumbuhan berdaun jarum lebih mudah terserang oleh jamur ini (Darma, 2004).

Upaya untuk mengatasi perubahan warna kayu dapat dilakukan baik dengan cara kimia, fisik maupun kombinasi dari kedua cara tersebut dengan pengaturan suhu dan kelembaban rendah. Penggunaan bahan kimia pengawet kayu diakui sebagai cara yang paling efektif dalam meningkatkan mutu dan produk kayu (UNEP, 1994). Penelitian ini bertujuan untuk mendapatkan data faktor penyebab dan teknologi pencegahan perubahan warna dengan sasaran memperoleh bahan dan cara yang dapat dipakai untuk meningkatkan kualitas kayu agar optimal dalam penggunaannya. Adapun hasil dari tulisan ini menyajikan nilai total variasi kecerahan $\left(\Delta \mathrm{L}^{*}\right)$ dan variasi warna $\left(\Delta \mathrm{E}^{*}\right)$ pada kayu jamuju dan kisampang yang diserut maupun tidak diserut.

\section{BAHAN DAN METODE}

\section{A. Lokasi Penelitian}

Penelitian dilakukan di Pusat Penelitian dan Pengembangan Keteknikan Kehutanan dan Pengolahan Hasil Hutan Bogor. Sedangkan pengujian hasil penelitian dilakukan di Pusat Penelitian Fisika, LIPI Bandung.

\section{B. Bahan dan Alat Penelitian}

Bahan kayu sebagai media pengujian digunakan kayu jamuju (Podocarpus imbricatus) dan kisampang (Evodia aromatica BL.) masing-masing mewakili kayu daun jarum dan kayu daun lebar. Bahan kimia yang digunakan adalah bahan yang bersifat antiseptik/desinsfektan dengan bahan aktif benzalkonium klorida, kresol (asam kresilat), dan metilena bis tiosianat. Peralatan yang digunakan antara lain, gergaji potong, gergaji belah, ampelas kayu, kaliper, spidol, eksikator, hand sprayer, bak plastik, kwas, kantung dan plastik lembaran, sarung tangan, masker, rol meter, hygrometer, dan termometer.

\section{Metode Penelitian}

1. Pengukuran suhu dan kelembaban relatif

Pengukuran suhu, kelembaban relatif (Rh), dan waktu dilakukan pada dua tempat pengujian, yaitu di tempat terbuka dan dalam ruangan. Hal ini bertujuan untuk memberikan keterangan (sebagai data penunjang) mengenai kondisi tempat dilakukannya pengujian.

\section{Uji efikasi kayu gergajian}

Uji efikasi kayu gergajian dilakukan dengan menggunakan tiga dolok dari setiap jenis pohon dengan panjang $1,20 \mathrm{~m}$, kemudian digergaji menjadi balok untuk contoh uji kayu segar berukuran $50 \mathrm{~cm} \times 5 \mathrm{~cm} \times 5 \mathrm{~cm}$. Dari setiap contoh uji diberi empat perlakuan yang berbeda, 
salah satunya dijadikan sebagai kontrol. Tiga perlakuan yang lain diberi MBT 2\%, serta benzalkonium klorida (formula C) dan asam kresilat (formula D) masing-masing dengan konsentrasi $0,3 \% ; 0,4 \%$; dan 0,5\%. Kayu dicelupkan ke dalam larutan selama lima menit atau banyaknya larutan yang menempel pada permukaan kayu berkisar antara 150-200 $\mathrm{ml}$ per $\mathrm{m}^{2}$. Contoh uji yang sudah diawetkan termasuk blanko disimpan dalam ruangan (di bawah atap) (Barly, dkk. 2012). Contoh uji ditumpuk dengan menggunakan pengganjal dari kayu yang sehat, ditutup dengan plastik agar udara dalam tumpukan tetap lembab. Pengamatan dilakukan setiap minggu selama empat minggu. Pengamatan pada minggu keempat selain pada bagian yang diserut juga pada bagian yang tidak diserut pada contoh uji. Intensitas serangan dinyatakan dalam persen, dihitung dengan cara membandingkan bagian luas permukaan serangan dengan seluruh luas permukaan contoh uji dengan bantuan lembar plastik transparan yang sudah dibuat gambar kotak. Data yang diperoleh ditabulasi dan dihitung rata-ratanya. Kriteria penilaian dan keadaan serangan jamur biru (blue stain) menggunakan metode Martawijaya dan Martono (1983). Pada setiap minggu, kadar air kayu dan kelembaban udara di dalam tumpukan dicatat. Penetapan kadar air dihitung dengan cara penimbangan berat contoh uji sebelum dan sesudah dikeringkan di tempat terbuka sampai bobot tetap, sedangkan penetapan kelembaban dengan menggunakan hygrometer. Pada akhir pengeringan kadar air dan warna kayu di permukaan dan dibagian dalam balok ditetapkan.

3. Uji efikasi dan perubahan warna selama pengeringan

Pada uji efikasi selanjutnya, dilakukan penggergajian pada dolok sisa untuk setiap jenis kayu menjadi papan berukuran $50 \mathrm{~cm}$ x $10 \mathrm{~cm}$ x 2,5 cm. Pemilihan contoh uji dilakukan secara acak dengan lima ulangan untuk setiap perlakuan termasuk kontrol, MBT 2\%, benzalkonium klorida (formula C), dan asam kresilat (formula D) masing-masing pada konsentrasi $0,3 \% ; 0,4 \%$; dan $0,5 \%$. Contoh uji dicelupkan ke dalam larutan selama lima menit atau banyaknya larutan yang menempel pada permukaan kayu berkisar antara 150-200 $\mathrm{ml}$ per $\mathrm{m}^{2}$. Contoh uji yang sudah diawetkan dengan bahan formula $\mathrm{C}$ dan $\mathrm{D}$ termasuk blanko disimpan di dalam ruang pengering. Pengeringan dilakukan pada suhu rendah maksimum $30^{\circ} \mathrm{C}$ dengan $\mathrm{Rh}$ kurang dari $70 \%$ dalam ruang ber-AC (Barly, dkk. 2012). Untuk pembanding dilakukan pengeringan dengan cara disimpan di tempat terbuka sampai bobot tetap. Penurunan berat contoh ditetapkan dengan cara ditimbang sebelum dan sesudah pengamatan. Selisih berat digunakan untuk menetapkan kadar air kayu. Selanjutnya, dari setiap perlakuan diambil satu contoh uji untuk pengukuran warna. Pengukuran kecerahan warna kayu dilakukan pada bagian yang diserut dan tidak diserut dengan menggunakan alat Colour Difference Meter CDX 105 buatan Murakam Colour Research Laboratory No.11-3, Kachidoki 3-Chome Tokyo, Japan dengan menggunakan diameter jendela 5 $\mathrm{mm}$. Nilai tristimulus X, Y, Z pada lima titik setiap contoh kemudian dirata-ratakan, sehingga diperoleh warna kayu sebagai berikut: $\mathrm{L}^{*}, \mathrm{a}^{*}, \mathrm{~b}^{*}$, $\Delta \mathrm{L}^{*}, \Delta \mathrm{a}^{*}, \Delta \mathrm{b}^{*}$, dan $\Delta \mathrm{E}^{*}$, berdasarkan Commission on Internationale de Enluminure (CIE) LAB dengan TAPPI T524 Om-79. Perubahan warna kayu dapat dihitung dengan menggunakan persamaan berikut (Gunther, 1986; Dubey et al., 2010)

$$
\left.\left.\Delta \mathrm{Eab}^{*}=\left[\left(\Delta \mathrm{L}^{*}\right) 2+\Delta \mathrm{a}^{*}\right) 2+\Delta \mathrm{b}^{*}\right) 2\right] \mathrm{i} / 2
$$

dimana $\Delta \mathrm{L}^{*}=\mathrm{L}^{*}$ setelah perlakuan $-\mathrm{L}^{*}$ sebelum perlakuan, $\Delta \mathrm{a}^{*}=\mathrm{a}^{*}$ setelah perlakuan $-\mathrm{a}^{*}$ sebelum perlakuan, $\Delta \mathrm{b}^{*}=\mathrm{b}^{*}$ setelah perlakuan $b^{*}$ sebelum perlakuan. Nilai L berkisar antara 0 (hitam) - 100 (clear), b- biru, b+ kuning, a- hijau dan a + merah, $\Delta \mathrm{E}^{*}=$ total variasi warna.

\section{Pengolahan data}

Analisis data dilakukan dengan menggunakan rancangan acak lengkap (RAL), dengan percobaan faktorial (A x B x C) dan (A x B) sebanyak lima ulangan. Analisis keragaman yang menunjukkan hasil berbeda nyata/signifikan diuji lebih lanjut dengan uji beda nyata jujur (BNJ) atau Tukey (Snedecor dan Cochran, 1980).

\section{HASIL DAN PEMBAHASAN}

\section{A. Kadar Air dan Kehilangan Berat Kayu Jamuju dan Kisampang}

Kerusakan kayu dapat dicirikan antara lain oleh kehilangan berat akibat serangan jamur. 
Sedangkan kadar air merupakan salah satu faktor yang mempengaruhi tingkat kerentanan kayu terhadap serangan jamur biru (blue stain). Hasil pengukuran kadar air dan kehilangan berat pada kayu jamuju dan kisampang di tempat terbuka dan dalam ruangan dapat dilihat pada Tabel 1 .

Kayu jamuju memiliki persentase kehilangan berat dan kadar air (Tabel 1) rata-rata lebih besar dibandingkan dengan kayu kisampang yaitu masing-masing sebesar 37,20\% dan 26,94\%. Sedangkan kayu kisampang memiliki persentase sebesar 34,45\% dan 22,40\%. Hal ini mungkin disebabkan kandungan zat ekstraktif yang dapat menghambat pertumbuhan jamur pada kayu jamuju lebih tinggi dibandingkan dengan kayu kisampang.

Tabel 1. Persentase kehilangan berat dan kadar air kayu jamuju dan kisampang Table 1. Weight loss and moisture content of jamuju and kisampang

\begin{tabular}{|c|c|c|c|c|}
\hline \multirow{2}{*}{$\begin{array}{l}\text { Keadaan } \\
\text { Condition }\end{array}$} & \multicolumn{2}{|c|}{ Jamuju } & \multicolumn{2}{|c|}{ Kisampang } \\
\hline & $\begin{array}{c}\text { Kehilangan berat } \\
\text { (Weight loss) \% }\end{array}$ & $\begin{array}{l}\text { Kadar air } \\
\text { (M.C) \% }\end{array}$ & $\begin{array}{c}\text { Kehilangan berat } \\
\text { (Weight loss) } \%\end{array}$ & $\begin{array}{l}\text { Kadar air } \\
\text { (M.C) \% }\end{array}$ \\
\hline $\begin{array}{l}\text { Tempat terbuka } \\
\text { (Outdoor) }\end{array}$ & 29,13 & 24,12 & 20,33 & 21,32 \\
\hline $\begin{array}{l}\text { Dalam ruangan } \\
\text { (Indoor) }\end{array}$ & 45,26 & 29,75 & 48,57 & 23,43 \\
\hline
\end{tabular}

\section{B. Sifat Efikasi Formulasi}

Nilai persentase rata-rata pewarnaan permukaan pada kayu gergajian kisampang dan jamuju disajikan pada Tabel 2.

Penggunaan formula C dan D pada konsentrasi 0,3 ; 0,4; dan $0,5 \%$ (v/v), baik pada kayu kisampang maupun jamuju (Tabel 2) tampak efektif mencegah blue stain dengan masa proteksi empat minggu. Hal ini diduga kayu kisampang dan jamuju berada pada kondisi kadar air rendah (Tabel 1), dimana dengan kondisi kadar air dibawah 30\% tidak ada air bebas pada rongga sel kayu, sehingga menghambat perkecambahan konidia atau spora dari jamur biru (blue stain), cenderung tidak membentuk apresorium atau apresorium kurang berkembang (Smith, 1977).

Tabe12. Nilai persentase rata-rata pewarnaan permukaan pada kayu gergajian kisampang dan jamuju sampai minggu ke-4.

Table 2. The average percentage value of sawn timber surface staining on kisampang and jamuju up to week-4

\begin{tabular}{ccccccccc}
\hline $\begin{array}{c}\text { Perlakuan } \\
\text { (Treatment })\end{array}$ & \multicolumn{9}{c}{ Kisampang } & \multicolumn{5}{c}{ Jamuju } \\
\hline (\% v/v) & 1 & 2 & 3 & 4 & 1 & 2 & 3 & 4 \\
\hline K & 2,5 & 7,5 & 7,5 & 7,5 & 20 & 22,5 & 25 & 25 \\
MBT 2 & 0 & 0 & 0 & 0 & 0 & 0 & 0 & 0 \\
C (0,3) & 0 & 0 & 0 & 0 & 0 & 0 & 0 & 0 \\
C (0,4) & 0 & 0 & 0 & 0 & 0 & 0 & 0 & 0 \\
C (0,5) & 0 & 0 & 0 & 0 & 0 & 0 & 0 & 0 \\
D $(0,3)$ & 0 & 0 & 0 & 0 & 0 & 0 & 0 & 0 \\
D $(0,4)$ & 0 & 0 & 0 & 0 & 0 & 0 & 0 & 0 \\
D $(0,5)$ & 0 & 0 & 0 & 0 & 0 & 0 & 0 & 0 \\
\hline
\end{tabular}

Keterangan (Remarks) : K = Kontrol contoh yang tidak diobat (untreated sample as control), MBT = Metilen bis tiosianat (methylene bis thiocyanate), $\mathrm{C}=$ Benzalkonium klorida, $\mathrm{D}=$ Cresylic acid 


\section{Kecerahan (Brightness)}

Hasil pengukuran total variasi kecerahan kayu jamuju dan kisampang dengan menggunakan alat Colour Difference Meter dapat dilihat pada Tabel 3.

Tabel 3 menunjukkan bahwa nilai kecerahan $\left(\mathrm{L}^{*}\right)$ kayu jamuju yang diberi bahan perlakuan pada bagian yang diserut hampir mendekati standar (94), yaitu 87,15 (D Luar), sementara pada kayu kisampang memiliki nilai 91,35 (K Bawah atap). Nilai kecerahan $\left(\mathrm{L}^{*}\right)$ kayu jamuju pada bagian yang diserut dan tidak diserut, yaitu 86,05 dan 82,70 dengan nilai total variasi kecerahan $\left(\Delta \mathrm{L}^{*}\right)$ terbesar, yaitu $-7,95$ dan $-11,30$ (K AC). Sedangkan nilai $\mathrm{L}^{*}$ kayu kisampang pada bagian yang diserut dan tidak diserut paling tinggi dari semua perlakuan, yaitu 89,80 dan 89,70 dengan nilai $\Delta \mathrm{L}^{*}$ paling besar yaitu $-4,20$ dan $-4,30$ (K AC). Tingginya nilai $\Delta \mathrm{L}^{*}$ pada dua jenis kayu dengan perlakuan $\mathrm{K}$ AC, mungkin disebabkan karena pada waktu pengeringan di ruang AC tidak terjadi proses oksidasi, hal ini menyebabkan inaktivasi enzim yang ada di dalam kayu, sehingga pembentukan warna coklat pada kayu tidak terjadi. Hal ini tentu saja sesuai dengan pernyataan Barly, dkk (2012), yang mengatakan bahwa penggunaan suhu dan kelembaban rendah dapat mempertahankan bahkan meningkatkan nilai kecerahan kayu.

Tabel 3. Total variasi kecerahan $\left(\Delta \mathbf{L}^{*}\right)$ dan variasi warna $\left(\Delta \mathbf{E}^{*}\right)$ pada bagian diserut dan tidak diserut kayu jamuju dan kisampang

Table 3. Total brightness variation $\left(\Delta L^{*}\right)$ and colour variation $\left(\Delta E^{*}\right)$ on the planed and unplaned of jamuju and kisampang timber

\begin{tabular}{|c|c|c|c|c|c|c|c|}
\hline \multirow{2}{*}{$\begin{array}{l}\text { Perlakuan } \\
\text { (Treatment) }\end{array}$} & \multirow{2}{*}{$\mathrm{S}$ dan TS } & \multicolumn{3}{|c|}{ Jamuju } & \multicolumn{3}{|c|}{ Kisampang } \\
\hline & & $\mathrm{L}^{*}$ & $\Delta \mathrm{L}^{*}$ & $\Delta \mathrm{E}^{*}$ & $\mathrm{~L}^{*}$ & $\Delta \mathrm{L}^{*}$ & $\Delta \mathrm{E}^{*}$ \\
\hline \multirow{2}{*}{ K Luar } & $\mathrm{S}$ & 86,85 & $-7,15$ & 20,68 & 91,15 & $-2,85$ & 8,80 \\
\hline & TS & 78,40 & $-15,60$ & 40,96 & 78,55 & 15,45 & 35,78 \\
\hline \multirow[t]{2}{*}{ C Luar } & S & 86,40 & $-7,60$ & 25,50 & 90,70 & $-3,30$ & 19,17 \\
\hline & TS & 72,60 & $-21,40$ & 41,02 & 71,10 & 22,90 & 40,19 \\
\hline \multirow{2}{*}{ D Luar } & S & 87,15 & $-6,85$ & 22,43 & 89,90 & $-4,10$ & 19,76 \\
\hline & TS & 76,30 & $-17,70$ & 38,69 & 76,65 & 17,35 & 37,92 \\
\hline \multirow{2}{*}{ MBT Luar } & $\mathrm{S}$ & 86,15 & $-7,85$ & 20,49 & 90,95 & $-3,05$ & 18,60 \\
\hline & TS & 74,35 & $-19,65$ & 38,58 & 72,25 & 21,75 & 40,07 \\
\hline \multirow{2}{*}{ K Bawah atap } & $\mathrm{S}$ & 86,95 & $-7,05$ & 24,04 & 91,35 & $-2,65$ & 22,56 \\
\hline & TS & 80,65 & $-13,35$ & 31,51 & 84,55 & $-9,45$ & 26,29 \\
\hline \multirow{2}{*}{ C Bawah atap } & S & 86,80 & $-7,20$ & 20,74 & 90,45 & $-3,55$ & 20,91 \\
\hline & TS & 79,50 & $-14,50$ & 29,57 & 81,90 & 12,10 & 31,72 \\
\hline \multirow{2}{*}{ D Bawah atap } & S & 86,50 & $-7,50$ & 25,08 & 90,60 & $-3,40$ & 21,43 \\
\hline & TS & 78,90 & $-15,10$ & 28,60 & 82,85 & 11,15 & 29,46 \\
\hline \multirow{2}{*}{$\begin{array}{l}\text { MBT Bawah } \\
\text { atap }\end{array}$} & S & 84,80 & $-9,20$ & 23,73 & 90,15 & $-3,85$ & 19,88 \\
\hline & TS & 81,60 & $-12,40$ & 35,46 & 85,00 & $-9,00$ & 25,68 \\
\hline \multirow[t]{2}{*}{$\mathrm{K} A \mathrm{C}$} & S & 86,05 & $-7,95$ & 25,57 & 89,80 & $-4,20$ & 18,59 \\
\hline & TS & 82,70 & $-11,30$ & 27,85 & 89,70 & $-4,30$ & 24,32 \\
\hline \multirow[t]{2}{*}{$\mathrm{CAC}$} & S & 86,00 & $-8,00$ & 21,87 & 89,50 & $-4,50$ & 20,23 \\
\hline & TS & 81,55 & $-12,45$ & 23,00 & 84,00 & 10,00 & 24,30 \\
\hline \multirow[t]{2}{*}{ D AC } & $\mathrm{S}$ & 86,45 & $-7,55$ & 25,65 & 90,40 & $-3,60$ & 18,06 \\
\hline & TS & 81,20 & $-12,8$ & 26,79 & 85,90 & $-8,10$ & 21,57 \\
\hline \multirow[t]{2}{*}{ MBT AC } & S & 83,70 & $-10,30$ & 21,84 & 90,55 & $-3,45$ & 21,22 \\
\hline & TS & 83,50 & $-10,50$ & 28,01 & 85,70 & $-8,30$ & 25,45 \\
\hline
\end{tabular}

Keterangan(Remarks): $\mathrm{K}=\mathrm{Kontrol}$ (Contro), $\mathrm{MBT}=$ Metilen bis tiosianat (Methylenee bis thiocyanate), $\mathrm{AC}=$ Air conditioning, $\mathrm{S}=\operatorname{Serut}($ Planed $), \mathrm{TS}=$ Tidak diserut $($ Unplaned $)$ 
jURNAL Penelitian Hasil Hutan Vol. 31 No. 3, September 2013: 213-220

Hasil sidik ragam total variasi kecerahan $\left(\Delta \mathrm{L}^{*}\right)$ dan kisampang baik yang diserut maupun tidak dan total variasi warna $\left(\Delta \mathrm{E}^{*}\right)$ pada kayu jamuju

diserut dapat dilihat pada Tabel 4 dan Tabel 5.

Tabel 4. Sidik ragam total variasi kecerahan $\left(\Delta \mathrm{L}^{*}\right)$ pada bagian diserut dan tidak diserut kayu jamuju dan kisampang

Table 4. Analysis of variance on the total brightness variation $\left(\Delta L^{*}\right)$ of the planed and unplaned jamuju and kisampang timber

\begin{tabular}{ccrrrl}
\hline $\begin{array}{c}\text { Sumber keragaman } \\
\text { (Source variance) }\end{array}$ & $\begin{array}{c}\text { DB } \\
(D F)\end{array}$ & JK $(S S)$ & KT $(M S)$ & $\begin{array}{c}\text { F-hitung } \\
\text { (F calculated) }\end{array}$ & $\operatorname{Pr}>$ F \\
\hline A & 1 & 8166,667 & 8166,667 & 1990,99 & $0,0001^{* *}$ \\
B & 11 & 1744,14 & 158,558 & 38,66 & $0,0001^{* *}$ \\
AB & 11 & 3663,57 & 333,052 & 81,2 & $0,0058^{*}$ \\
C & 1 & 13,776 & 13,776 & 3,36 & 0,0684 \\
AC & 1 & 3248,704 & 3248,704 & 792,02 & $0,0001 * *$ \\
BC & 11 & 1389,936 & 126,358 & 30,81 & $0,0001 * *$ \\
ABC & 11 & 3943,346 & 358,486 & 87,4 & $0,0001 * *$ \\
\hline
\end{tabular}

Keterangan (Remarks): A = Jenis kayu (Type of wood); B = Perlakuan (Treatment); $\mathrm{C}=$ Penyerutan $($ Plane); DB = Derajat bebas (Degrees of freedom); JK = Jumlah kuadrat (Sum of squares); KT = Kuadrat tengah (Mean square); ${ }^{*}$ Nyata (Significant); $* *=$ Sangat nyata (Highly significant)

Tabel5. Sidik ragam total variasi warna $\left(\Delta \mathrm{E}^{*}\right)$ pada bagian diserut dan tidak diserut kayu jamuju dan kisampang

Table 5. Analysis of variance on the total color variation $\left(\Delta E^{*}\right)$ of the planed and unplaned jamuju and kisampang timber

\begin{tabular}{ccrrrl}
\hline $\begin{array}{c}\text { Sumber keragaman } \\
\text { (Source variance })\end{array}$ & DB $(D F)$ & JK $(S S)$ & KT $(M S)$ & $\begin{array}{c}\text { F-hitung } \\
(\text { F calculated })\end{array}$ & $\operatorname{Pr}>$ F \\
\hline A & 1 & 548,432 & 548,432 & 24,30 & $0,0001^{* *}$ \\
B & 11 & 1810,718 & 164,610 & 7,29 & $0,0001^{* *}$ \\
AB & 11 & 540,538 & 49,140 & 2,18 & $0,0172^{*}$ \\
C & 1 & 6141,828 & 6141,828 & 272,12 & 0,0684 \\
AC & 1 & 33,675 & 33,675 & 1,49 & $0,0001^{* *}$ \\
BC & 11 & 2964,380 & 269,489 & 11,94 & $0,0001^{* *}$ \\
ABC & 11 & 205,627 & 18,693 & 0,83 & $0,0001^{* *}$ \\
\hline
\end{tabular}

Keterangan (Remarks): A = Jenis kayu (Type of wood); B = Perlakuan (Treatment); $\mathrm{C}=$ Penyerutan $($ Plane); DB $=\mathrm{Derajat}$ bebas (Degrees of freedom); JK = Jumlah kuadrat (Sum of squares); KT = Kuadrat tengah (Mean square); $*$ Nyata (Significant); $* *=$ Sangat nyata (Highly significant)

Tabel 4 dan 5 menunjukkan bahwa faktor jenis kayu, perlakuan, interaksi jenis kayuperlakuan dan interaksi jenis kayu-penyerutan, serta interaksi perlakuan-penyerutan berpengaruh sangat nyata terhadap kecerahan dan warna kayu, sedangkan faktor penyerutan baik pada kayu jamuju maupun kisampang tidak berpengaruh nyata terhadap kecerahan dan warna kayu. Pada penelaahan lanjutan dengan uji jarak beda nyata jujur/Tukey (BNJ) total variasi warna $\left(\Delta \mathrm{E}^{*}\right)$ kayu jamuju dan kisampang dapat dilihat pada Tabel 6. 
Tabel 6. Uji jarak beda nyata jujur/Tukey $(\mathrm{BNJ})$ total variasi warna $\left(\Delta \mathrm{E}^{*}\right)$ kayu jamuju dan kisampang

Table 6. Honestly significant difference/Tukey test total color variation of jamuju and kisampang timber

\begin{tabular}{|c|c|c|c|c|}
\hline \multirow{2}{*}{ No. } & \multirow{2}{*}{ Faktor (Factor) } & \multirow{2}{*}{$\begin{array}{l}\text { Kode faktor } \\
\text { (Factor code) }\end{array}$} & \multicolumn{2}{|c|}{$\begin{array}{l}\text { Total variasi warna (Total color variation } \\
\qquad\left(\Delta \mathrm{E}^{*}\right)\end{array}$} \\
\hline & & & Rata-rata (Average) & $\begin{array}{l}\text { Klasifikasi } \\
\text { (Classification) }\end{array}$ \\
\hline \multirow[t]{2}{*}{1} & Jenis kayu (Type of wood) (A) & a1 & 27,82 & A \\
\hline & & a2 & 24,79 & B \\
\hline \multirow[t]{2}{*}{2} & Perlakuan (Treatment) (B) & b2 & 31,47 & A \\
\hline & & b10 & 22,35 & $\mathrm{C}$ \\
\hline \multirow[t]{2}{*}{3} & Penyerutan (Planing) (C) & c2 & 31,37 & A \\
\hline & & $\mathrm{c} 1$ & 21,25 & B \\
\hline \multirow[t]{2}{*}{4} & Kombinasi faktor (Factor combination) (T) & $\mathrm{t} 4$ & 41,02 & A \\
\hline & & $\mathrm{t} 5$ & 8,8 & I \\
\hline
\end{tabular}

Tabel 6 menunjukkan bahwa kayu jamuju memiliki nilai $\mathrm{E}$ lebih tinggi daripada kayu kisampang, dan perlakuan C Luar memiliki nilai rata-rata paling tinggi dibandingkan semua perlakuan pada tempat lain yaitu 31,47. Hal ini diduga karena kayu jamuju yang diberi formula $\mathrm{C}$ (benzalkonium klorida) dan dipaparkan langsung di bawah sinar matahari mudah terurai, sehingga nilai variasi warna kayu meningkat.

Dengan mengetahui faktor penyebab perubahan warna pada kayu maka usaha untuk mempertahankan warna alami yang indah akan lebih mudah untuk dilakukan (Herawati, 2005). Namun demikian kemampuan mata manusia melihat variasi kecerahan (brightness variation) lebih besar skala tiga (Phelps et al., 1994) atau jumlah nilai variasi warna lebih besar dari dua (Sundqvist, 2002) dalam Dubey (2010).

\section{KESIMPULAN}

\section{A. Kesimpulan}

1. Perubahan warna oleh jamur biru (blue stain) dipengaruhi oleh beberapa faktor antara lain tingginya kelembaban $(\mathrm{RH})$, suhu udara, dan kadar air dalam kayu yang tinggi. Selain itu, tingginya kadar pati dan gula serta rendahnya kadar ekstraktif yang terdapat pada kayu dapat menjadi penyebab rentannya kayu terhadap serangan blue stain.

2. Penggunaan bahan antiseptik berupa bahan kimia MBT 2\%, benzalkonium klorida (formula C) dan kresol atau asam kresilat (formula D) masing-masing dengan konsen-trasi $0,3 \% ; 0,4 \%$; dan $0,5 \%$ merupakan cara efektif untuk mengatasi pertumbuhan blue stain, sehingga kecerahan dan warna alami kayu dapat dipertahankan. Selain itu, penggunaan suhu dan kelembaban rendah dapat meningkatkan kecerahan dan warna kayu.

3. Hasil stabilisasi warna yang dilakukan pada kayu jamuju dan kisampang adalah sebagai berikut.

a. Kayu jamuju

Kecerahan kayu jamuju pada bagian yang diserut dapat dipertahankan hingga nilai kecerahan (L*) mencapai 87,15 (D Luar). Sedangkan pada bagian yang tidak diserut dapat dipertahankan hingga nilai kecerahan (L*) mencapai 82,70 (K AC). Selain itu, perlakuan (treatment) yang memiliki nilai kecerahan $\left(\mathrm{L}^{*}\right)$ pada bagian yang diserut dan tidak diserut paling tinggi dari semua perlakuan, yaitu kontrol AC (K AC) dengan nilai total variasi kecerahan terbesar $\left(\mathrm{L}^{*}\right)$, yaitu -7,95 dan -11,30.

b. Kayu kisampang

Kecerahan kayu kisampang pada bagian yang diserut dapat dipertahankan hingga nilai kecerahan ( $\mathrm{L}^{*}$ ) mencapai 91,35 (K Bawah atap), dimana nilai ini hampir mendekati standar nilai 
(94). Sedangkan kecerahan pada bagian kayu yang tidak diserut dapat dipertahankan hingga nilai kecerahan (L*) mencapai 89,70 (K AC). Selain itu, perlakuan (treatment) yang memiliki nilai kecerahan $\left(\mathrm{L}^{*}\right)$ pada bagian yang diserut dan tidak diserut paling tinggi dari semua perlakuan, yaitu kontrol AC ( $\mathrm{K} \mathrm{AC})$ dengan nilai total variasi kecerahan terbesar $\left(\Delta \mathrm{L}^{*}\right)$, yaitu $-4,20$ dan $-4,30$.

\section{DAFTAR PUSTAKA}

Balfas. 1998. Penanggulangan Warna pada Kayu (Tusam, Karet, dan Ramin) untuk Furniture dan Bangunan. Di dalam: Prosiding Ekspose Hasil-hasil Penelitian, AEK Nauli: BPK Pematang Siantar, 1998. hlm 75-81.

Barly; A. Ismanto; D. Martono \& Abdurachman. 2012. Pengawetan Warna Kayu Tusa Pinus merkusii) dan Pulai (Alstonia sp.) dengan Menggunakan Bahan Dasar Disinfektan. Jurnal Penelitian Hasil Hutan, 30 (2) : 156.

Boyce JS. 1961. Forest Pathology. 3rd Ed. McGrawHill Book Company. New York.

Darma, I.G.K. Tapa. 2004. Blue Stain, Perusak Warna Kayu. Makalah Pribadi Falsafah Sains (PPS 702) Institut Pertanian Bogor.

Dubey, M. K., S. Pang \& J.Walker 2010. Color and dimensional stability of oil heat-treated Radiata Pinewood after accelerated UV weathering. Forest Prod. J. 60(5): 453-459.
Ginanjar, R. R. 2011. Sifat dan Jadwal Pengeringan Tiga Jenis Kayu Rakyat (Altingia excelsa, Quercus spp, dan Podocarpus imbricatus). [skripsi]. Bogor: Fakultas Kehutanan. Institut Pertanian Bogor.

Gunter, K. 1986. Experimental Techniques and Practical Application. Hauser Publishers, Munich, Vienna New York.

Herawati, E. 2005. Warna alami kayu. E-USU Repository@2005. Universitas Sumatera Utara. [Diakses pada Tanggal 4 April 2013].

Martawijaya, A dan D. Martono. 1983. Dichlofluanid sebagai Pestisida untuk Proteksi Papan Ramin terhadap Jamur Biru. Prosiding Pertemuan Ilmiah Pengawetan Kayu. Badan Penelitian dan Pengembangan Kehutanan Jakarta.

Martono. 2005. Pola serangan dan cara pencegahan jamur biru Prosiding Seminar Hasil Penelitian Hasil Hutan, Puslitbang Teknologi Hasil Hutan, Bogor 30 Nopember 2005.

Smith, R. 1977. Wood Decayed Fungi and It's Prevention. Risborough Research Laboratory. Princetown, London.

Snedecor, G.W. and W.G. Cochran. 1980. Statistical Methods. Fifth edition. Iowa State Univ. Press. Ames, Iowa.

UNEP. 1994. Environment aspect of Industrial Wood Preservation. A technical Guide. Technical Report Series No.20 UNEP IE/PAS. Paris. 